\title{
"BANCA DEL FARE" SUMMER SCHOOL IN ALTA LANGA: «THE RUINS TO BE REBUILT WILL BE OUR CLASSROOMS». KNOWLEDGE FROM ARTISANS TO NEW GENERATIONS, FROM ANCIENT SKILLS TO NEW BUILDING TECHNIQUES.
}

\author{
$\underline{\text { M. Villata }}^{\mathrm{a}}$ \\ a Polytechnic of Turin, Turin, Italy - maurizio.villata@studenti.polito.it
}

Commission VII, Education: courses, workshops, summer schools... developing new professional skills

KEY WORDS: Cultural Heritage, knowledge, recovery, re-use, traditional and new building techniques, rural architecture, GIS

\begin{abstract}
:
"Banca del fare" is an ambitious project proposed by "Cultural Park Alta Langa". It is born to hand ancient knowledges down to young people, as meeting place useful to exchange the development of new construction techniques and at the same time the traditional ones. A program of educational workshops, which constitute the summer school, was organized for increasing communication among different generations. Indeed, the last local craftsmen or artisans are coming out from their employment and there is no training process to ensure the migration of knowledge to young architects. The activities of the school took place for the first time during summer of 2016 in Alta Langa, the southern part of Langhe in Piedmont. The landscape of this area is marked by small rural architectures called "ciabòts" shed all over the countryside. Artisans and students work together to recover these buildings every year. The aim of this landscape heritage's valorization is to relate the restored ciabòt into a network, in order to create a widespread hotels system. Therefore, the essay wants to present the results of "Banca del fare" and to suggest a GIS project that can gather information about numerous "ciabòt" widespread in this territory. The interaction between land development and networking process can ensure the optimal reuse of these rural architectures.
\end{abstract}

\section{INTRODUCTION}

The essay deal with the actual issue about migration of knowhow from elder artisans to young architects. "Banca del Fare" summer school wants to attempt a mending between different generations, in order to hand down a considerable traditional building knowledge and to revive these territories.

\subsection{Developers}

"Parco Culturale Alta Langa"1 is a nonprofit association working in the southern part of Langhe, in Piedmont. Its main aims are promoting the knowledge of the territory (historical, literary, architectural, gastronomic) and developing tourism and training processes against the growing marginalization of this area. 
The educational project "Banca del Fare" is supported by Polytechnic of Turin, namely trough prof. Silvia Belforte, prof. Andrea Bocco and prof. Carlo Ostorero ${ }^{2}$. Constant presence of tutors on the building site, arch. Nadia Battaglio and arch. Lorenzo Serra, ensure the progress of workshops, conducting the activities with the artisans and experts in the field: Gilberto Quarneti $^{3}$, Armando Calosso ${ }^{4}$, Piero Dotta ${ }^{5}$, Danilo Dianti ${ }^{6}$, Giovanni Bertola ${ }^{7}$, Andrea Zanini ${ }^{8}$, Merlino Zeldenthuis ${ }^{9}$.

\subsection{The "Alta Langa" area}

Alta Langa is located in the southern part of Langhe's region in Piedmont. Starting after the Second World War, this rural area was described by farmer's poverty and it is dealing till today with the continuous depopulation and decay of agricultural and architectural heritage. The migration trend lasted a long time, even because of water pollution that affected this area in the last decades of the twentieth century ${ }^{10}$.

Nowadays the beauty of Langhe's landscape was drawn to attention by UNESCO, that in 2014 proclaimed cultural landscape the norths part of Langhe characterized by the highquality wine production. Alta Langa instead, excluded from UNESCO borders, maintains the polyculture aspect deriving from its characteristic subsistence agriculture.

The GTL (Gran Traversata delle Langhe) is a long pedestrian path that cross this area, it allows to observe all the elements of the landscape like fields, "ciabòt", castles and villages.

2 "Banca del Fare" was made possible with the support of Compagnia di San Paolo, Fondazione CRT and CRC.

3 Mastro Scuola d'Arte Muraria "Calchèra San Giorgio", Grigno (Trento).

4 Carpenter interested in the future of the wood and craftsmanship.

5 Architect involved in local restorations.

6 Restorer and master of mortar.

$7 \quad$ Artisan and master of stone.

8 Carpenter and restorer of wood.

9 Master Dutch builder, expert in wood construction techniques.

10 See the case of ACNA, the factory in Cengio that polluted the Bormida river during much of the twentieth century (Belforte, 1993)

\subsection{The goal}

The Summer School will embrace the architectural educational program that can allow an active re-use of the buildings, regenerating the demographic and economic aspect of the territory.

\section{VALORIZATION OF THE LANDSCAPE HERITAGE}

\subsection{The "ciabòt"}

"Ciabòt" represents an "embroidery" of the landscape. They were tied up to the activities of the fields because the farmers who worked on the land often could not return to their home. Thus, they built these small two story houses. The simplicity of these architectures is related to economic, social, cultural and functional reasons.

The two main construction materials are the stone and the chestnut wood derived from the environment. The stone is a compact and calcareous sandstone used both for rustic and religious buildings, with similar techniques.

"Ciabòt" can be considered a basic component of the territory. In a large-scale analysis they can represent a great widespread system. For this reason, several solutions of reuse have been imagined (Ottaviani, Pezzolla and Piscioneri, 2015):

- Rooms for workers; the workers receive room and board in exchange for their labour.

- Rooms for tourists.

- $\quad$ Spaces for tasting local products.

- Widespread hotel system.

- $\quad$ Resting places for GTL's walkers.

- Restauration's laboratories.

Among these possibilities, "Parco Culturale Alta Langa" chose to pursue the widespread hotel system, considering the transformation from agricultural destination to a cultural and touristic one.

Therefore, these abandoned dwellings, representing the historical memory of the rural past grows on the territory, become the objects of intervention. The small scale of the buildings allows the annual laboratories to face the various phases of their recovery.

\subsection{Summer School 2016}

The main actions taken in the Summer School 2016 are good practice example of restoration localized in Cascina Crocetta ${ }^{11}$. They are mainly referred to (Fig. 1; 1-5-6 areas of intervention): dry stone walls (Fig. 2), the reconstruction of a roof made of

11 Traditional farmhouse located in a small stone village, 500 meters above sea level, Castelletto Uzzone $(\mathrm{CN})$ 
stone slabs (called "ciape") (Fig. 3), natural hydraulic lime plasters (Fig. 4) and a new wooden enlargement of a building (Fig. 5).

The eight courses were organized in practical workshops of construction and testing of traditional building techniques and conservative recovery. Each course consisted of four training sessions: practical workshops, deepening workshops, conferences and events, tours and discovery trails.

Workshops allow to practice and experiment in scale $1: 1$, by analysing and understanding buildings through direct contact. The buildings to be recovered were "classrooms" and master craftsmen were the teachers, assisted by young architects who have already experienced such techniques on the field.

The deepening workshop, hosted by teachers and experts of architecture's technology and of building materials, consisted in theorical and practical teaching about the traditional and innovative building technologies.

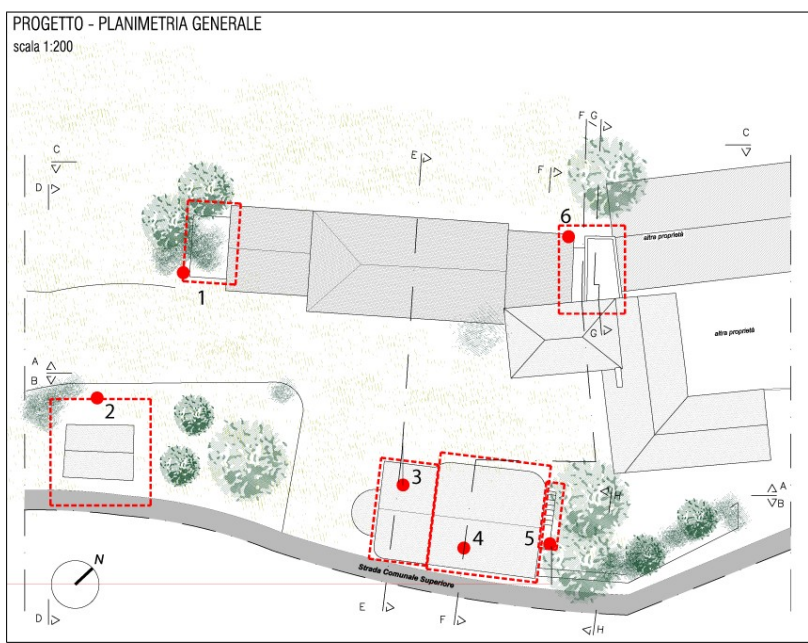

Figure 1. Areas of intervention in Cascina Crocetta.

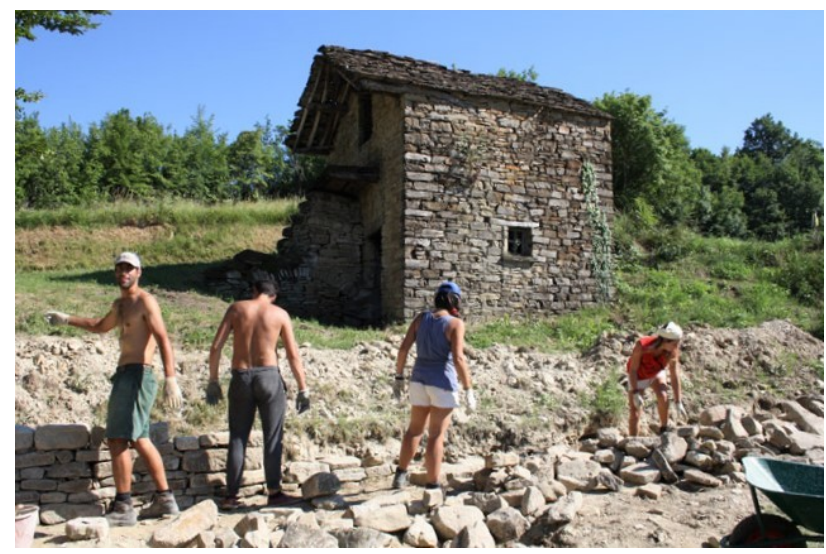

Figure 2. The construction of a dry-stone wall

Conferences were held by leading figures in the field of historical restoration, anthropology, self-construction, experimentation of innovative materials and techniques, and study of new scenarios of territorial development.
The participants, during the practical work, were divided into up to five people teams. The hours of work amounted to a total of 102 every two weeks, 57 of practice and 45 of theory.

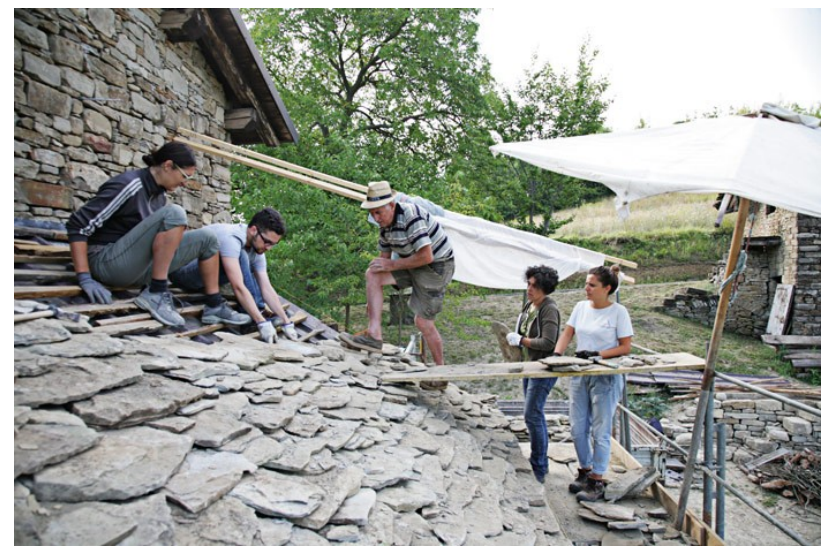

Figure 3. The reconstruction of a roof

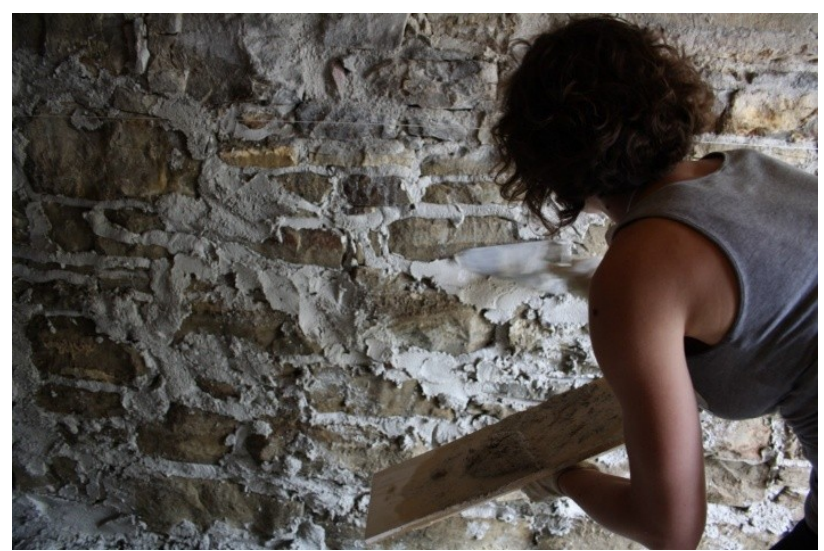

Figure 4. Use of natural hydraulic lime plasters

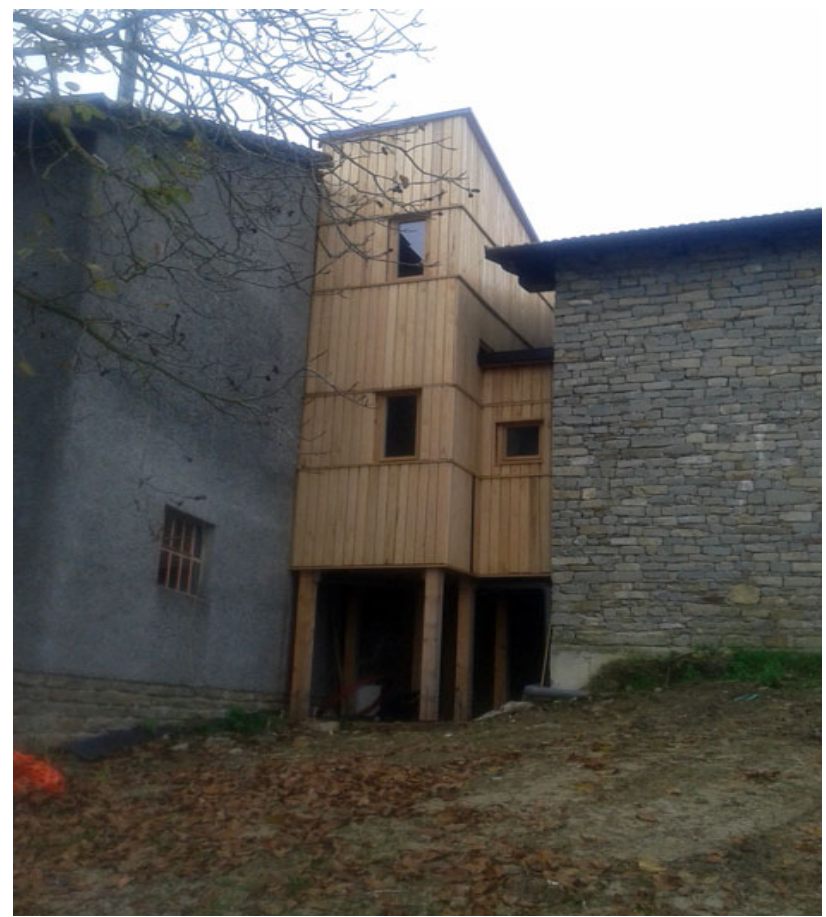

Figure 5. New wooden enlargement of the dwelling. 
- Year of intervention

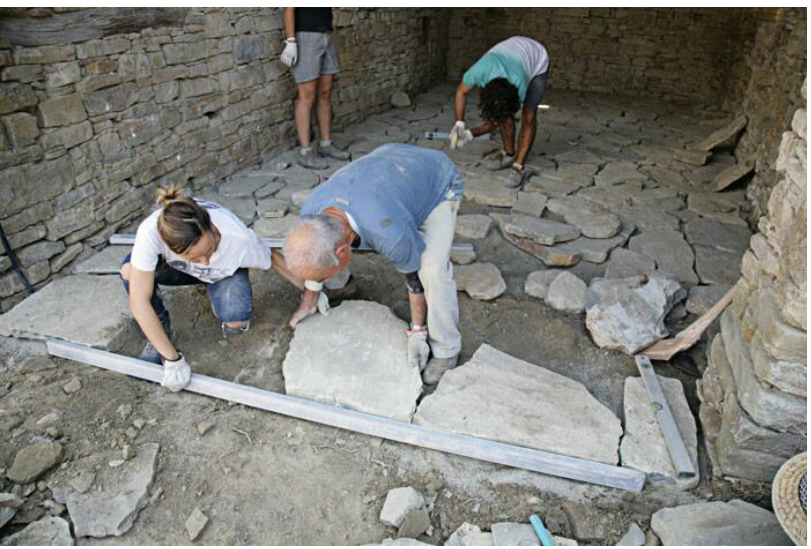

Figure 6. Laying a traditional stone floor

\subsection{Summer School 2017}

The second edition of "Banca del Fare" wants to complete all the restoration of Cascina Crocetta (Fig. 1; 2-3-4 areas) within the summer of 2017.

The workshops will handle especially:

- $\quad$ old chestnuts's drier (“Scau”),

- coverages's recovery in stone plates of two "ciabòt" and their conversion of use from store to residence,

- realization of a new drywall following the traditional techniques,

- recovery of the "ciabot"'s wooden floors.

- to make the plaster and stucco of natural hydraulic lime,

- wooden restoration of ancient furniture.

The Summer School consists of seven workshops from the $18^{\text {th }}$ of June to the $24^{\text {th }}$ of September 2017.

\section{GIS PROJECT}

\subsection{GIS for the Summer School}

It is possible to create a GIS project in order to network the information about every restored "ciabòt". GIS project could play an active role in the future management of widespread hotel system.

The data to be gathered could be manifold, for instance:

- Year of construction

\section{- Historical documents}

\author{
- Documents of the project \\ - Origin of materials \\ ○ Duration of the work \\ $\circ \quad \cdots$
}

Thanks to this update of territorial geo-referred information, it is possible to go along with the restauration of the shed "ciabòt" in Alta Langa, also assuring a territorial development in the field of historical knowledge.

\section{CONCLUSIONS}

In conclusion, it is possible to summarize that "Banca del fare" sets three main goals:

1. Establishing a model for the formation of a new generation of craftsmen, technicians and planners, able to support the growing demand of recovery and which can ensure the continuous and programmed maintenance of the traditional architectural heritage. as As in the ancient art workshops, the educational commitment of local artisans can work closely with young people.

2. Creating a model, accessible to all (professionals, administrators and community) consisting of a set of best practices open to visitors. With the intention to offer to the tourists the idea of housing and historical conditions together with the contemporary expectations of comfort and earthquake safety. In addition, the developed project aims to reinforce the knowledge realizing that the longstanding traditions have had a beginning, and can also evolve.

3. Starting a young social cooperative, which can perform several functions:

- ensuring the school's management, workshops and conferences,

- ensuring the logistics and continuity to the project,

- entering the goods recovered in an economically sustainable common system of tourist hospitality.

The creation of the social cooperative, besides the obvious employment benefits for young people, wants to encourage collaboration with other players on the territory to create a useful touristic system. 


\section{REFERENCES}

Ottaviani, A., Pezzolla, M. and Piscioneri, M. Guida al recupero dei ciabòt in Alta Langa. Supervisor Bocco, A. Politecnico di Torino, Corso di Laurea in Architettura Costruzione Città, 2015

Belforte S. (ed.), Oltre l'ACNA: identità e risorse per la rinascita della Valle Bormidà, Franco Angeli, Milano, 1993

Bocco A., Cavaglià G., Flessibile come di pietra. Tattiche di sopravvivenza e pratiche di costruzione nei villaggi montani, Celid, Torino, 2008 